\title{
Spatio-temporal dimension of lightning flashes based on three-dimensional Lightning Mapping Array
}

\author{
Jesús A. López ${ }^{\mathrm{a}, ~}{ }^{*}$, Nicolau Pineda ${ }^{\mathrm{a}, \mathrm{b}}$, Joan Montanyàa, Oscar van der Velde ${ }^{\mathrm{a}}$, Ferran Fabróa ${ }^{\mathrm{a}}$, David Romero ${ }^{\mathrm{a}}$ \\ ${ }^{a}$ Lightning Research Group, Technical University of Catalonia, Edifici TR1, Carrer Colom 1, Terrassa 08222, Spain \\ ${ }^{\mathrm{b}}$ Meteorological Service of Catalonia, Carrer Berlín 38-46, Barcelona 08029, Spain
}

\section{ARTICLE INFO}

\section{Keywords:}

Cloud lightning

Spatial and temporal flash dimensions

Ellipse fitting

Lightning Mapping Array

\begin{abstract}
A B S T R A C T
3D mapping system like the LMA - Lightning Mapping Array - are a leap forward in lightning observation. LMA measurements has lead to an improvement on the analysis of the fine structure of lightning, allowing to characterize the duration and maximum extension of the cloud fraction of a lightning flash. During several years of operation, the first LMA deployed in Europe has been providing a large amount of data which now allows a statistical approach to compute the full duration and horizontal extension of the in-cloud phase of a lightning flash. The "Ebro Lightning Mapping Array" (ELMA) is used in the present study. Summer and winter lighting were analyzed for seasonal periods (Dec-Feb and Jun-Aug). A simple method based on an ellipse fitting technique (EFT) has been used to characterize the spatio-temporal dimensions from a set of about 29,000 lightning flashes including both summer and winter events. Results show an average lightning flash duration of $440 \mathrm{~ms}$ (450 ms in winter) and a horizontal maximum length of $15.0 \mathrm{~km}$ (18.4 km in winter). The uncertainties for summer lightning lengths were about $\pm 1.2 \mathrm{~km}$ and $\pm 0.7 \mathrm{~km}$ for the mean and median values respectively. In case of winter lightning, the level of uncertainty reaches up to $1 \mathrm{~km}$ and $0.7 \mathrm{~km}$ of mean and median value. The results of the successful correlation of CG discharges with the EFT method, represent $6.9 \%$ and $35.5 \%$ of the total LMA flashes detected in summer and winter respectively. Additionally, the median value of lightning lengths calculated through this correlative method was approximately $17 \mathrm{~km}$ for both seasons. On the other hand, the highest median ratios of lightning length to CG discharges in both summer and winter were reported for positive CG discharges.
\end{abstract}

\section{Introduction}

The characterization of lightning is of fundamental interest in many fields, from storm warning and public safety applications to the design of lightning protection systems. One of the most basic parameters that define a lightning flash is its total duration. Although it might seem that this is a trivial measurement to do, the impossibility to observe inside the cloud by means of optical instruments, combined with the wide scale of lightning, have restricted the instrumentation to remote electromagnetic measurements. In such case, the wide spectrum of electromagnetic emissions of different lightning processes and the requested wide dynamic range of sensitivity add more complexity to the determination of the start and end of a lightning flash. Since the initial attempts, some discrepancy resulted between different measurements. Bruce and Golde (1941), Schonland (1956) and Pierce (1955) obtained flash durations of the order of $0.25 \mathrm{~s}$. Later Brook and Kitagawa (1960) defined the total duration of a lightning flash as the time interval between the first burst of pulse activity and the last detectable R-or K-change pulse. Under this criterion they obtained a median duration of $0.5 \mathrm{~s}$, which was consistent with later measurements by Ogawa and Brook (1964). Lightning research carried out in India by Aiya and Lakshminarayan (1965) and Sastry (1970) found that the duration of lightning flashes is related to the thunderstorm lightning activity. They found that the average duration of lightning flashes decreases when lightning rates are high.

Another basic parameter that defines a lightning flash is its total extension. This parameter has been less studied due to the same restrictions in the use of optical instruments and the large range of extension that a lightning flash can show. With the advent of detection systems like the VHF Lightning Mapping Array (LMA) (Rison et al., 1999; Thomas et al., 2003; Goodman et al., 2005), which detects radiation

\footnotetext{
* Corresponding author.

Email address: jesus.alberto.lopez@upc.edu (J.A. López)
} 
produced by lightning breakdown processes, has enable a qualitative leap forward into the analysis of the cloud phase lightning. The LMA system allows detailed analysis of individual flashes, through the mapping of the lightning channels in the cloud with sufficient time resolution and spatial precision to locate the origin and propagation of each flash throughout a storm's life cycle. Relying on LMA data, Defer et al. (2003) and more recently, Thomas et al. (2013) have estimated the total length of lightning channels. Such a measurement is important to estimate NOx per flash among other lightning properties. Bruning and MacGorman (2013) demonstrated studying LMA data that the extension of lightning is related to the storm intensity. They have shown that lightning flashes near strong updrafts, tend to be more frequent and smaller whereas those occurring far from strong vertical drafts were larger and less frequent. These authors used a combination of flash rate and area in order to compute an energy spectrum of lightning flashes, finding the maximum flash energy at sizes of about $10 \mathrm{~km}$. In our previous works (Montanyà et al., 2014a) we provided the first distributions of size and duration of lightning flashes occurring in north-eastern Spain.

The knowledge of the distribution of the duration and the maximum extension of lightning flashes is of importance for several practical aspects. It is worth noticing that lightning location systems (LLS) detect cloud-to-ground (CG) strokes, which have to be grouped later into flashes. The grouping of strokes into flashes allows for the estimation of the ground flash density $(\mathrm{Ng})$ parameter. In practice this parameter has many implications such as risk assessment and lightning protection systems such as described by Montanyà et al. (2016), March (2016), IEC-62305-2 (2013).

The common stroke-to-flash grouping standard (e.g. Cummins et al., 1998) uses spatio-temporal criteria like a maximum duration for a flash, the maximum distance between strokes, and a maximum inter-stroke interval. Lightning warning methods are also based on the occurrence of lightning within monitoring areas. Tuning warning alarms requires the knowledge of the horizontal extension of lightning size to monitoring areas.

In a similar way, observation of lightning from space also requires the knowledge of the expected flash duration and size. With the recent launch of the Lightning Mapper (GLM) aboard the GOES-R series (Geostationary Operational Environmental Satellites) (Goodman et al., 2013) the exploitation of new applications derived from optical lightning measurements will continue to gain interest. Contrary to ground-based LLS, geostationary sensors observe thunderstorms from above, and flash type discrimination (ground or cloud flash) is hindered by the optical thickness of the thundercloud. The algorithms that are being developed to isolate lightning events and to determine flash type on the GLM data (e.g. Koshak and Solakiewicz, 2011) require accurate information on lightning duration and spatial extension.

The World Meteorological Organization has recently published an update on the world's record of the longest detected distance for a single lightning flash and the longest detected duration for a single lightning flash (Lang et al., 2016). Two majestic lightning flashes are presented, one with an extension of $321 \mathrm{~km}$ and the second with duration of $7.74 \mathrm{~s}$.

All in all, improvements to lightning remote sensing techniques have allowed new in-sight on the characterization of lightning dimensions. In this paper we compute the duration and horizontal extension of a set of about 29,000 lightning flashes mapped by the first LMA deployed in Europe. A simple ellipse fitting method is proposed to estimate the horizontal lightning flash extension and total duration. We distinguish lightning events related to summer and winter thunderstorms. Finally, uncertainties are quantified.

The organization of this paper is as follows. Section 2 describes data; Section 3 the method; Section 4 is dedicated to the results;
Section 5 provides a general discussion and finally Section 6 presents the summary.

\section{Data}

Data of the Lightning Mapping Array (ELMA) are used in the present study. An LMA system was deployed in 2011 in the Ebro Delta (NE Iberian Peninsula, Fig. 1), the six station network was expanded to 11 stations during 2012, enlarging the area of coverage. The base-lines of the sensors range from 6 to $27 \mathrm{~km}$. More details on the ELMA can be found in van der Velde and Montanyà (2013)andPineda et al. (2016). The ELMA station distribution and coverage is depicted in Fig. 1. The LMA system (e.g. Rison et al., 1999) detects lightning radio emissions in the very high frequency range (VHF, 60-66 MHz) and locates them in three dimensions by a time-of-arrival technique which uses at least five stations. Each station samples the maximum signal amplitude and its GPS-derived precise time over $80 \mu$ intervals, allowing locating 2000 to 3000 sources per second during lightning flashes. Accuracy of the LMA systems is described in Thomas et al. (2003).

Cloud-to-ground data information is provided by the European LINET network. LINET employs the time-of-arrival (TOA) technique to detect CG lightning strokes in the very low frequency range Betz et al. (2009a). More details about LINET network can be found in Betz et al. (2009b).

A lightning flash clustering algorithm is applied to the LMA data source, to segregate the large numbers of individual radiation sources into discrete lightning flashes (McCaul Jr et al., 2009). Here we have used the flash algorithm developed by van der Velde and Montanyà (2013), adapted from Thomas et al. (2003). The algorithm groups LMA sources that are separated by less than $150 \mathrm{~ms}$ in time. In this case only flashes with more than 50 sources have been selected and a set of about 29,000 flashes, containing summer and also winter lightning from the 2012-2015 period is used. An example of ELMA detection for an individual flash is depicted in Fig. 2.

\section{Method}

The LMA technology is able to accurately capture and map the lightning leaders that spread in different forms and directions through the cloud. Accurate flash clustering and noise removal are crucial to determine flash extension, as LMAs suffer from noise of several types. Misplaced or mistimed sources are hard to remedy by flash clustering algorithms (McCaul Jr et al., 2005) and the remaining residual noise should be avoided to correctly estimate flash dimensions. Bruning and MacGorman (2013) calculated the flash horizontal extension by means of a convex hull function (plan view). The convex hull is the polygon produced by allowing a rubber band to contract on all the points constituting the flash (Devadoss and O'Rourke, 2011). The convex hull allows defining the geometry instead of imposing an assumed form (Bruning and MacGorman, 2013). However, the polygon defined by the convex hull may have a complicated shape and may contain a lot of nodes, including noisy sources. In our case, bearing in mind that we are aiming to estimate simple parameters like the maximum horizontal extension and duration, we have opted for a simple method.

Notable in this regard are the techniques of geometric primitives fitting that allow for the reduction and simplification of data and, consequently, faster and simpler processing (i.e. Fitzgibbon et al., 1999). A very important primitive is an ellipse, which is exploited in several fields such as astronomy, physics, biology, medical imaging, industrial inspection, robotics, see Maini (2005) for details. Regarding meteorological applications, elliptical shapes have been used to depict the shape of convective rain cells (i.e. Karklinsky and Morin, 2006; Barnolas et al., 2010; Renard et al., 2012). In fact, ellipses have widely 


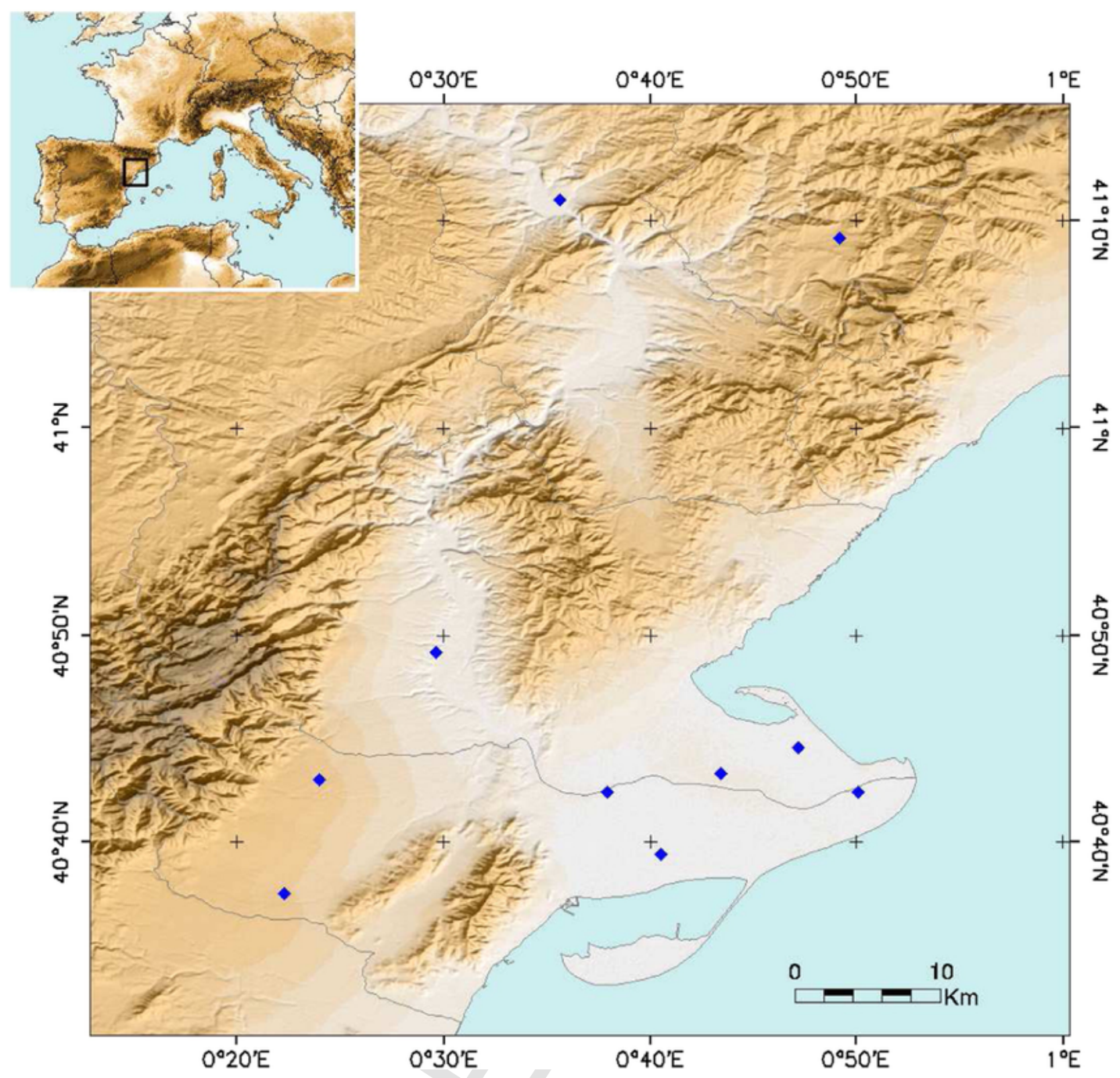

Fig. 1. ELMA sensors on the delta of the Ebro River (NE Iberian Peninsula) and ELMA approximate coverage area. Source: Adapted from Pineda et al. (2016).

been used to represent location errors in LLS (e.g. Cummins and Murphy, 2009; Gander et al., 1994). Different methods have been proposed for ellipse fitting in literature: Hough transform (e.g. Leavers, 1992), Kalman filtering (e.g. Porrill, 1990), fuzzy clustering (Dave and Bhaswan, 1992), or least squares approach (e.g. Bookstein, 1979). Our method is based on a simple ellipse fitting technique ( $E F T)$ similar to the method used by Montanyà et al. (2014a) where ellipses are used to simplify the extension of lightning flashes. In general, the ellipse equation can be represented by a sum of the squares of independent, normally distributed data which is represented conforming to the chi-square distribution function (Orechovesky, 1996). In this case, the chi-square distribution is defined by two degrees of freedom, its likelihood value represents the scale of the ellipse, and it must satisfy a specific confidence interval.

\subsection{Confidence intervals and ellipse fitting}

The EFT can be applied conforming to different confidence intervals (percentage of the samples to be analyzed) that rely on the Standard Deviation value $(S D)$ of the normal distribution function. Six confidence intervals have been considered: $68 \%, 78 \%, 83 \%, 89 \%, 92 \%$, and $95 \%$. We assume the ELMA locations being independent, normally distributed and the sum of their squares being conformal to the chi-square distribution function.
Fig. 3 shows an example of the EFT over a bunch of the VHF sources belonging to the same lighting flash, as detected by the ELMA. In this example, the fitting ellipses are shown as a sequence of overlapping ellipses, corresponding to the six confidence intervals used. The points remaining outside the elliptical contour will not be part of the flash. These sources are considered to depict residual noise. On the other hand, they can be used to indicate the uncertainty of the method.

After the EFT, once each flash is represented by the corresponding ellipse, the lengths of the ellipse were computed according to the covariance matrix (Orechovesky, 1996; Ray and Srivastava, 2008; Wang et al., 2015). The length of the major axis is used to estimate the lightning maximum length.

\subsection{Method validation}

Regarding the uncertainty of the EFT and bearing in mind the aim of the study, we shall select the confidence interval most suitable for the estimation of the length of the flash. In this regard, a manual lightning length computation was conducted and the results are used as reference values to identify the remaining residual noise of the samples. In Fig. 3 the blue line represents the major axis of the ellipse manually computed and reproduces the principal trajectory through which the lightning channel can grow according to the ELMA data. This trajec- 


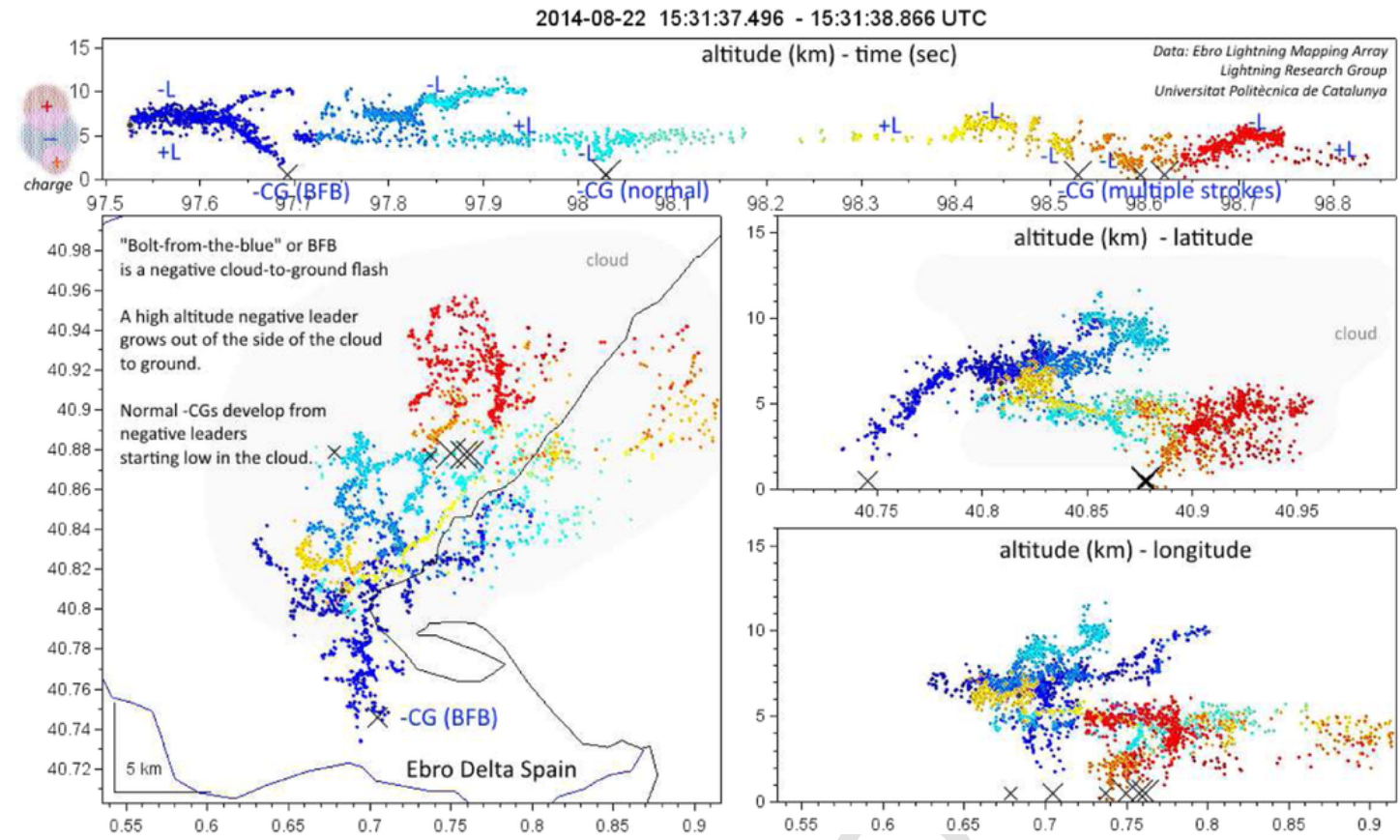

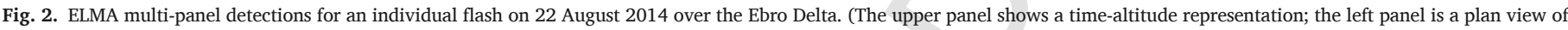

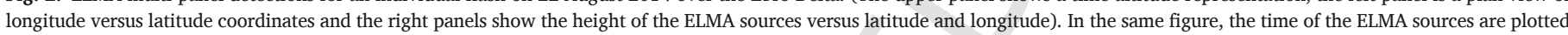

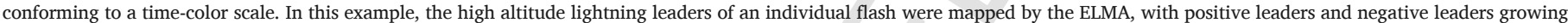

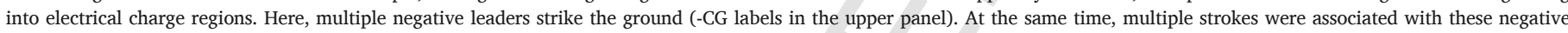

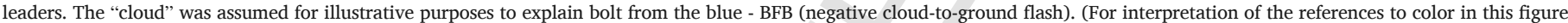
legend, the reader is referred to the web version of this article.)

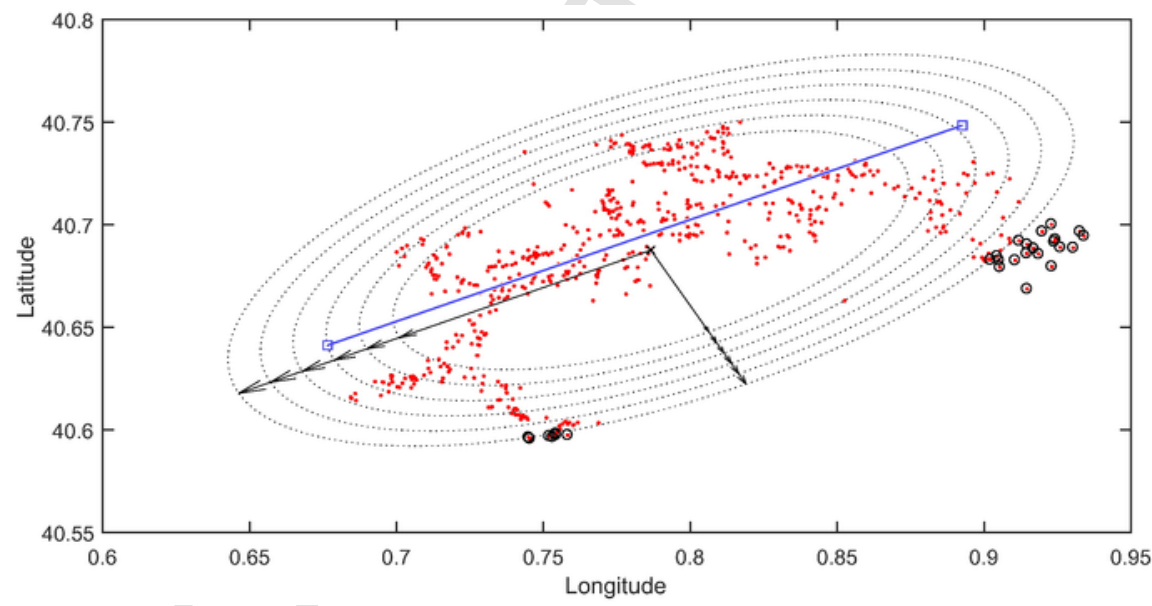

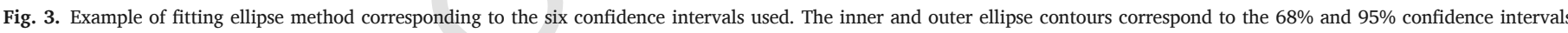

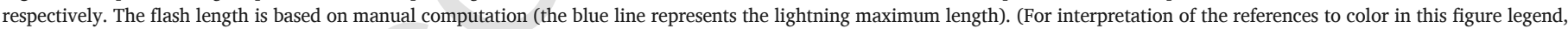
the reader is referred to the web version of this article.)

tory can reflect a good approximation of the maximum length of lightning.

\subsection{Paired analysis}

A paired analysis between EFT method and the manual lightning length computation was performed; in order to select the confidence interval for the EFT that best suits the flash maximum extension. The manual length computation was carried out on a sample of 1285 flashes, including both summer and winter cases. Cases were selected conforming to a simple sample size test. As a result, the minimal difference of paired analysis tests was adopted as the best lightning length estimation and the elliptical method error was deduced from this finding. The next section shows the principal findings.

\section{Results}

\subsection{Paired analysis}

The principal results of the paired comparison analysis for the major axis of the ellipse according to EFT methodology during winter and summer lightning flashes, are summarized in Fig. 4. According to the mean and the median values for summer lightning for each confidence interval, absolute lengths between $1.2 \mathrm{~km}$ to $9 \mathrm{~km}$ and $0.7 \mathrm{~km}$ to $7.2 \mathrm{~km}$ were obtained (mean and median respectively). For winter lightning, absolute lengths reached values between $1 \mathrm{~km}$ to $14.6 \mathrm{~km}$ and $0.7 \mathrm{~km}$ to $12.1 \mathrm{~km}$, mean and median value respectively. In both 


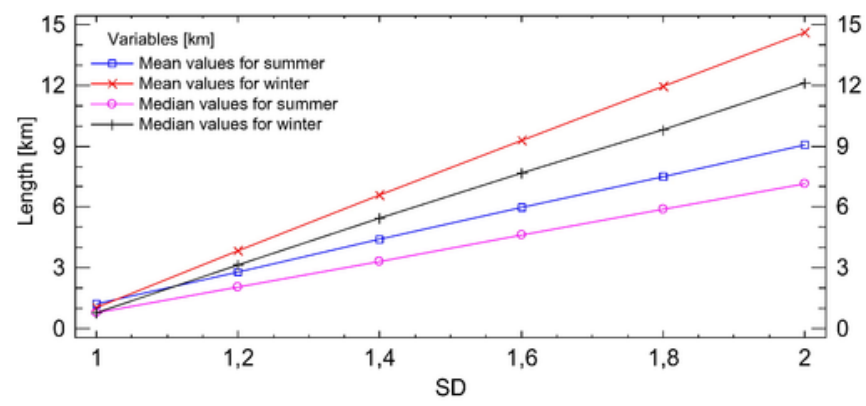

Fig. 4. Paired analysis test for summer and winter lightning derived from ELMA network.

cases these measures of central tendency indicate a noticeable variability when the SD of the EFT method is greater than 1.2.

It is worth mentioning that the paired difference of mean and median values between two consecutive confidence intervals were hover around $1.6 \mathrm{~km}$ and $2.3 \mathrm{~km}$ respectively. These values should represent the rate of uncertainty increase for each SD. The same figure shows

Table 1

Summer and winter lightning length relevant results derived from the EFT.

\begin{tabular}{lll}
\hline & Summer & Winter \\
\hline Samples & 28,527 & 351 \\
Mean $(\mathrm{km})$ & 15.0 & 18.4 \\
Median $(\mathrm{km})$ & 10.3 & 15.6 \\
Standard dev $(\mathrm{km})$ & 13.9 & 10.9 \\
Percentile 5th $(\mathrm{km})$ & 3.8 & 5.9 \\
Percentile 95th $(\mathrm{km})$ & 42.1 & 39.2 \\
Maximum $(\mathrm{km})$ & 143.2 & 70.1 \\
\hline
\end{tabular}

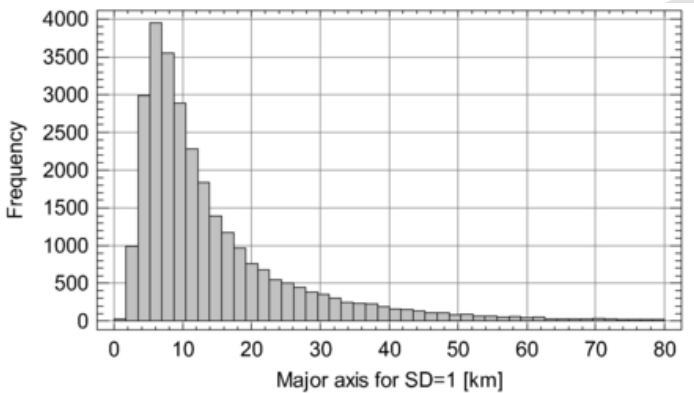

(a) Frequency distribution of the lightning lengths in summer.

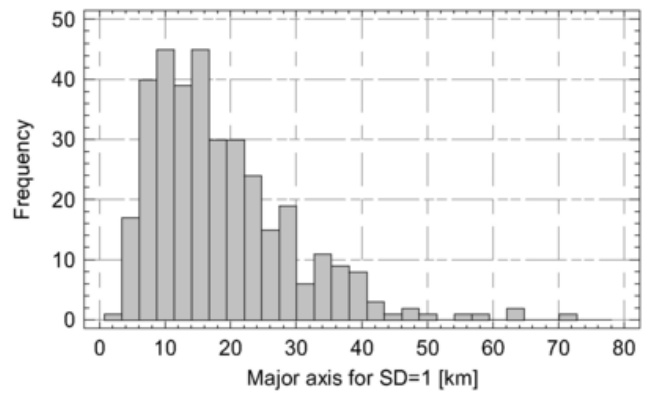

(c) Frequency distribution of the lightning lengths in winter. that the paired results for each confidence interval during summer and winter storms present a remarkable difference when the SD is greater than 1.4 (e.g. for a SD equal to 1 the difference is about $0.2 \mathrm{~km}$ ). This difference rises to $5.5 \mathrm{~km}$ when SD is equal to 2 for the mean values).

According to previous results one can see that the best confidence interval for the EFT is provided by a SD of 1 . In this case the uncertainty of the method may reach about $1.2 \mathrm{~km}$ and $0.7 \mathrm{~km}$ for the mean and median values respectively for summer lightning. In case of winter lightning these values were about $1 \mathrm{~km}$ and $0.7 \mathrm{~km}$ for the mean and median values respectively. For our purpose we assume these uncertainties.

\subsection{Lighting size estimation}

Table 1 shows the statistical results of the major axis of the ellipses. In this case the spatial resolution for 28,527 and 351 summer and winter lightning events were analyzed respectively. As shown in this table, the lengths of summer lightning reach values about $15 \mathrm{~km}$ and $10.4 \mathrm{~km}$ for mean and median values respectively. In the case of winter lightning events, the mean and median values were approximately $18.5 \mathrm{~km}$ and $15.5 \mathrm{~km}$ respectively. These findings show that, in the region of study, winter lightning is longer than that of summer lightning, with a mean and median length of about $3.4 \mathrm{~km}$ and $5.3 \mathrm{~km}$, respectively. It is worth noticing that the maximum length registered was about $143 \mathrm{~km}$, corresponding to a lightning flash that occurred during a summer storm.

Fig. 5 shows the frequency and cumulative distributions of lightning lengths for winter and summer thunderstorms respectively. According to the frequency distributions (left panel) we note that the data set in both cases (winter and summer) can be adjusted to a log-normal distribution function with standard deviation values displayed in Table 1.

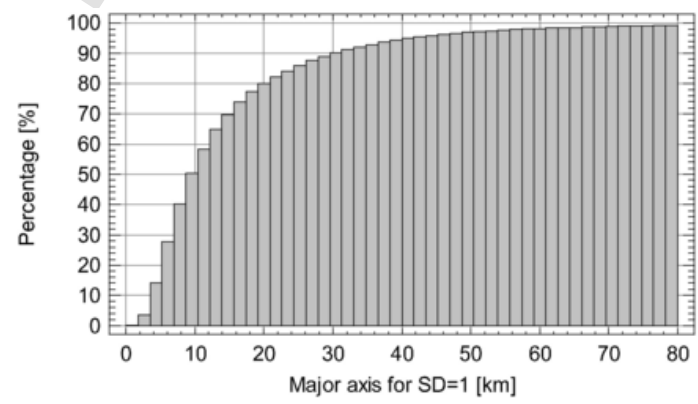

(b) Cumulative distribution of the lightning lengths in summer.

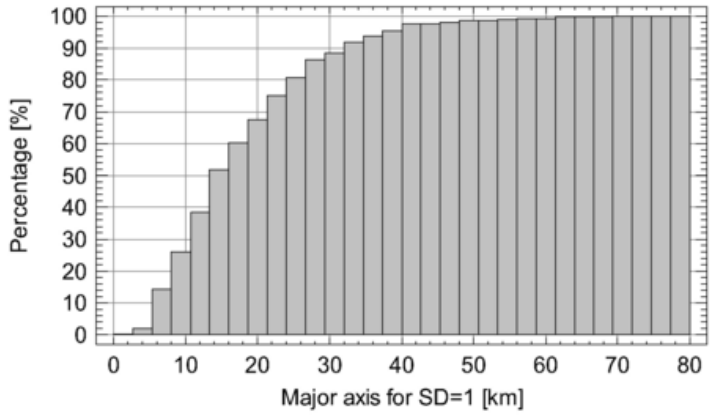

(d) Cumulative distribution of the lightning lengths in winter.

Fig. 5. Lightning length distribution for winter and summer thunderstorms derived form the ELMA network. 
The same figure in the right panel shows the cumulative distribution for the lightning lengths. In this case, $90 \%$ of summer lightning has an approximate length of $30 \mathrm{~km}$ or below, while this figure is about $35 \mathrm{~km}$ for winter lightning. Thus, the length difference between summer and winter lighting for $90 \%$ of dataset is about $5 \mathrm{~km}$.

\subsection{Lightning flash duration}

Lightning durations were estimated according to the difference between the first and the last LMA lightning source for each $S D$ value and for each individual flash. Table 2 shows the statistical results obtained from the dataset. The mean and median duration values of summer lightning are about $438 \mathrm{~ms}$ and $354 \mathrm{~ms}$, respectively. For winter lightning, durations of about $452 \mathrm{~ms}$ and $413 \mathrm{~ms}$ as mean and median values were found. Regarding maximum durations of lightning, values up to $2.4 \mathrm{~s}$ and $1.8 \mathrm{~s}$ for summer and winter were reached respectively. In general the central tendency values of lightning duration in both seasons were found to be similar.

Fig. 6 shows the frequency and cumulative distribution of the winter and summer lightning durations. It can be noticed that both lightning seasons durations, can be adjusted to a log-normal distribution

Table 2

Summer and winter lightning duration results derived from the EFT.

\begin{tabular}{lll}
\hline & Summer & Winter \\
\hline Samples & 28,527 & 351 \\
Mean (s) & 0.44 & 0.45 \\
Median (s) & 0.35 & 0.41 \\
Standard dev (s) & 0.31 & 0.25 \\
Percentile 5th (s) & 0.15 & 0.11 \\
Percentile 95th (s) & 1.05 & 0.94 \\
Maximum (s) & 2.39 & 1.82 \\
\hline
\end{tabular}

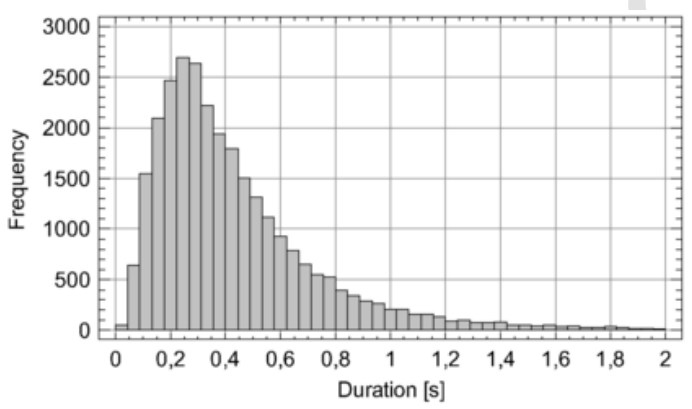

(a) Frequency distribution of the lightning durations in summer.

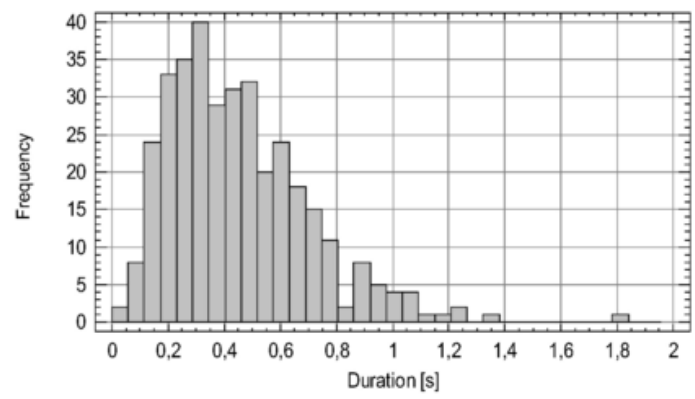

(c) Frequency distribution of the lightning durations in winter. function (Fig. 6 left panels), as was the case with the lightning lengths. The right panels of the figure show the cumulative distribution of lightning durations, where $90 \%$ of lightning achieved a duration of approximately $800 \mathrm{~ms}$ or below in both cases.

On the other hand, the inter-flash time durations for consecutive flashes were computed according to the time difference between the last and the first LMA source for successive flashes. In this case, all LMA sources per flash inside coverage region were employed. As results, the averages of inter-flash time were around $16 \mathrm{~s}$ and $144 \mathrm{~s}$ for summer and winter respectively. Regarding their median values, these were about $3 \mathrm{~s}$ for summer lightning and $29 \mathrm{~s}$ in winter. Finally, the frequency distributions of these results can be adjusted to a log-normal distribution function in both seasons as shown in Fig. 7.

\subsection{Analysis of CG flashes}

A complementary analysis about the type of lightning detection (intracloud with CG strokes versus intracloud without CG strokes) has been conducted. In addition to the analysis of the size and duration, the ratio between flash length and CG stroke peak current have been calculated. This ratio has been obtained for flashes with single and multiple CG strokes, polarity and season. In practice, the precise identification of a lightning flash with cloud-to-ground strokes is not evident and it is well known that, in some cases, lightning location systems can report some intracloud lightning processes as CG strokes (e.g. Cummins et al., 1998). Based on the previous reference, in this work we consider as CG strokes those detections with absolute values of peak current greater than $10 \mathrm{kA}$. Spatial and temporal limits of the comparative analysis were formulated according to the EFT results with a confidence interval of $68 \%$.

As results, Table 3 shows the comparative analysis of LMA flash detections associated with CG discharges. A total of 1981 summer and

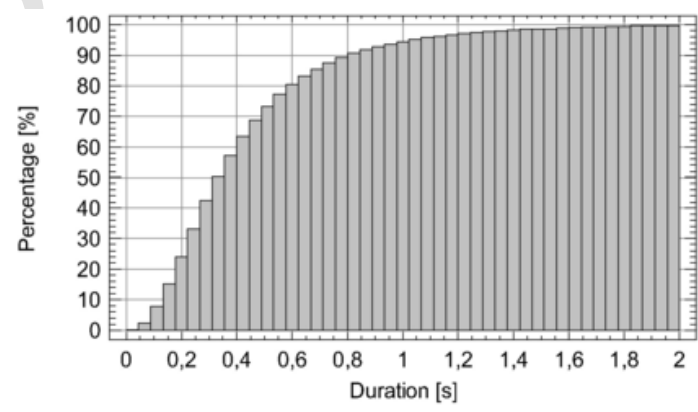

(b) Cumulative distribution of the lightning durations in summer.

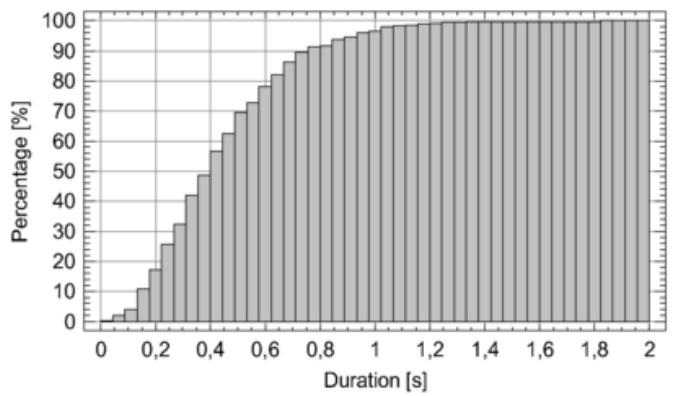

(d) Cumulative distribution of the lightning durations in winter.

Fig. 6. Frequency and cumulative distributions of lightning duration derived from the ELMA. 


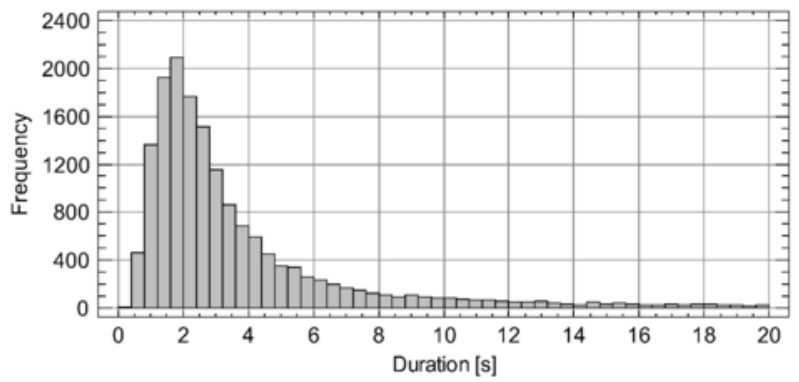

(a) Frequency distribution of the inter-flash time duration in summer.

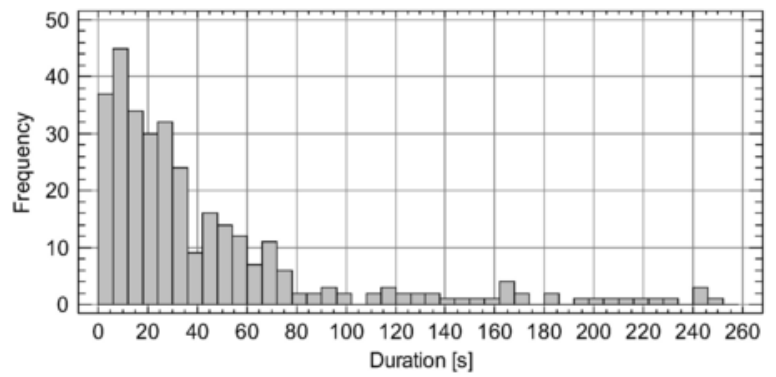

(b) Frequency distribution of the inter-flash time duration in winter.

Fig. 7. Inter-flash time duration for summer and winter ELMA flashes.

Table 3

Comparative results of LMA flash detections with CG discharges.

\begin{tabular}{lll}
\hline CG discharge & Summer & Winter \\
\hline Samples & 1981 & 125 \\
Negative [\%] & 4.5 & 28.2 \\
Positive [\%] & 2.4 & 7.4 \\
Total [\%] & 6.9 & 35.6 \\
\hline
\end{tabular}

125 winter CG flashes were successfully correlated, indicating IC:CG ratios of about $6.9 \%$ and $35,5 \%$ in each respective season. The highest IC:CG ratio was observed in winter for negative CG discharges. On the other hand, the median values of lightning lengths correlated with CG discharges were about $17.9 \mathrm{~km}$ and $16.9 \mathrm{~km}$ for summer and winter lightning respectively. The same analysis was carried out for lightning durations, whose median values were about $0.57 \mathrm{~s}$ and $0.48 \mathrm{~s}$ for both summer and winter lightning respectively. Comparing these results with lightning durations derived from the EFT method (see Table 2), there is no significant difference between the two.

The ratio between lightning length, polarity, and peak current value of CG discharges are presented in Table 4. Before discriminating between single and multiple strokes, the results suggest that the median length/current ratio of positive CG discharges was greater than that of

Table 4

Median of the length/current ratio.

\begin{tabular}{lllll}
\hline & Summer & \multicolumn{3}{c}{ Winter } \\
\hline Length/current & Negative & Positive & Negative & Positive \\
\hline $\mathrm{km} / \mathrm{kA}$ & 1.06 & 1.27 & 0.85 & 1.31 \\
$\mathrm{~km} / \mathrm{kA}$ (single) & 1.13 & 1.26 & 0.97 & 1.32 \\
$\mathrm{~km} / \mathrm{kA}$ & 0.98 & 1.47 & 0.61 & 1.29 \\
(multiple) & & & &
\end{tabular}

negative discharges and these values were about 1.3 in summer and winter. Considering CG discharges with single and multiple strokes separately, a similar relationship was found between negative and positive discharges in both season. It is important to note that, the lightning flashes with positive multiple CG strokes were about $11 \%$ and $7 \%$ in summer and winter respectively. These values were consistent with values reported by several authors (Saba et al., 2010; Qie et al., 2013; Hazmi et al., 2017), who obtained values of about $5 \%$ and $18 \%$ conforming to high-speed observations and flat-plate parallel antennas measures.

\subsection{Ellipse eccentricity}

An easy way to synthesize the shape of an ellipse and by extension the shape of the lighting, is through the eccentricity, a measure of how nearly circular the ellipse is. The eccentricity is simply calculated by dividing the major and minor axes and therefore can present values from 0 to 1 ; where 1 corresponds to a circle (same length of both axes). It is worth mentioning that the eccentricity of the ellipses can be described according to distribution function shown in Fig. 8. The frequency distribution of the analyzed sample has a negative skew, with a longer tail to lower values of eccentricity. About $10 \%$ of the ellipses have an eccentricity below 0.5 (the major axis doubles to minor axis), approximately $44 \%$ is between 0.5 and 0.75 and the majority of the ellipses (approx. $55 \%$ ) has an eccentricity above 0.75 (the difference between both axes is below $25 \%$ ).

\section{Discussion}

An ellipse fitting technique (EFT) has been used to characterize the horizontal extension and duration of the cloud phase of lightning flashes, which in fact by extension characterizes the whole phenomena, as it encompasses the ground strikes. On average, a lightning flash lasts for about $440 \mathrm{~ms}$ ( $450 \mathrm{~ms}$ in winter) and has an horizontally maximum length of about $15.0 \mathrm{~km}$ (18.4 km in winter). The frequency distribution of the analyzed sample has a positive skew, with a longer tail to higher values both for length and duration (Figs. 5-6 panels a and c). Relying on the median, a flash lasts for about $350 \mathrm{~ms}$ ( $410 \mathrm{~ms}$ in winter) and has a maximum length of about $10.4 \mathrm{~km}$ ( $15.6 \mathrm{~km}$ in winter). Besides from the intrinsic value of these figures in the characterization of lightning, they have a practical interest, for example in the stroke-to-flash grouping techniques.

It is worth recalling that conventional LLS detect cloud-to-ground strokes, not flashes. As most lightning applications rely on flashes (e.g. lightning flash density for a given area, $\mathrm{Ng}$ ), a grouping algorithm is needed. Commonly, algorithms to group strokes into flashes are based on a space-time criterion (Rakov and Huffines, 2003). For example, in the NLDN (National Lightning Detection Network covering the contiguous United States), strokes are added to any active flash for a specified time period (usually $1 \mathrm{~s}$ ) after the first stroke, as long as the additional

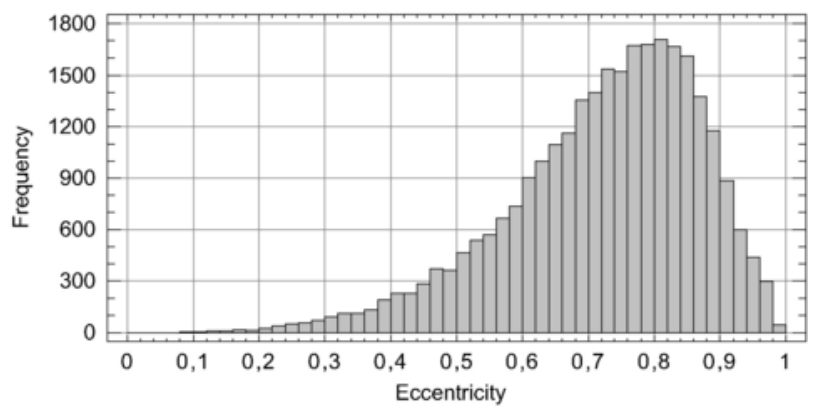

Fig. 8. Frequency distributions of the ellipse eccentricity (summer dataset). 
strokes are within a specified clustering radius (usually $10 \mathrm{~km}$ ) of the first stroke and the time interval from the previous stroke is less than a maximum inter stroke interval (usually $500 \mathrm{~ms}$ ) (Cummins et al., 1998). Conversely, Yair et al. (2014), relying on results obtained by "video-multiplicity" studies (e.g. Stall et al., 2009; Saba et al., 2010; Ballarotti et al., 2012), suggested narrowing the stroke grouping criteria, using a distance equal to twice the location accuracy of the LLS (e.g. $2.5 \mathrm{~km}$ ) an inter-stroke duration of $200 \mathrm{~ms}$ and no restrictions about the maximum flash duration. In this regard, the figures obtained in the present study cast doubt on the appropriateness of the $10 \mathrm{~km}$ of radius proposed by Cummins et al. (1998). Our results show that $90 \%$ of the lightning are between 3.8 and $42.1 \mathrm{~km}$ (percentiles 5th and 95th), but half of the summer lighting have a length exceeding the $10 \mathrm{~km}$ or less. The winter median is larger (median of $15.6 \mathrm{~km}$ ), but percentiles 5 th and 95th are rather similar to the summer ones.

Another aspect to take into consideration while setting a grouping criteria is that some of the multiple strokes of a flash may use the same path and strike in the same point, while sometimes a subsequent stroke may use a new path and create a new ground contact. In function of the maximum distance considered in the clustering algorithm (e.g. $10 \mathrm{~km}$ ) this new ground contact may be treated as a new flash, regardless of the time elapsing from the preceding stroke.

With the advent of systems like the LMA, cloud channels are mapped into detail, allowing the identification of the negative stepped leaders to ground van der Velde and Montanyà (2013). Mixing this information with CG locations from conventional LLS, ground strike points (GSP) belonging to the same flash can be identified. In fact, half of the downward negative CG flashes exhibit multiple ground strike points (hereafter GSP), resulting in an average number of GSP per flash ranging from 1.5 to $1.7 \mathrm{GSP} /$ flash with a mean separation distance in the order of $1.8 \mathrm{~km}$ (Pédeboy and Schulz, 2014). As mentioned, Fig. 2 shows an example of multiple cloud-to-ground strikes with multiple strokes associated with downward negative leaders. In that case, the negative cloud-to-ground strikes belonged to the same flash and the average separation of strokes was about $12 \mathrm{~km}$.

The difference between IC:CG ratio values in both summer and winter lightning is significant, resulting from the different thunderstorm types occurring in summer and winter (e.g. Price and Rind, 1993; Boccippio et al., 2001).

On the other hand, the median values of the lightning length associated with CG discharges, including multiples strokes, was approximately $17 \mathrm{~km}$ in both summer and winter, and this value was greater than those of the median values of the lightning lengths obtained according to the EFT (see Table 1). The relationship between lightning length and current of CG discharges for single and multiple strokes (km/ $\mathrm{kA}$ ratio values) tended to be greater for positive CG discharges than for negative ones. This result is in accordance with the assumption that positive flashes have extensive horizontal channels as has been observed by Saba et al. (2010).

For clustering strokes belonging to the same flash, the criteria relying on the location accuracy of the LLS suggested by Yair et al. (2014), seems adequate, but if the clustering should include all new ground contacts corresponding to the same flash then the $10 \mathrm{~km}$ of radius proposed by Cummins et al. (1998) may be too short, according to our results.

Regarding flash duration, our results show that, in the area of study, $50 \%$ of the summer lightning last for about $350 \mathrm{~ms}$ or less, and $90 \%$ of the flashes are between 0.11 and $1.05 \mathrm{~s}$ (percentiles 5th and 95th). Even if there is reliable evidence of durations exceeding $1 \mathrm{~s}$ (e.g. Lang et al., 2016; Bruning and MacGorman, 2013; Bruning and Thomas, 2015; Montanyà et al., 2014b), the present results suggest to keep $1 \mathrm{~s}$ as the time period as the maximum time period, as almost $95 \%$ of the analysed sample is below $1 \mathrm{~s}$.
For the inter-flash time analysis, averages between $16 \mathrm{~s}$ and $144 \mathrm{~s}$ for summer and winter lightning were found respectively. This value is related to the flash-rate of thunderstorms and may depend on the storm's life cycle as suggested by Stano et al. (2010). They found three different distributions of inter-flash time for isolated storms derived from the LDAR network (Rustan et al., 1980). In that case, inter-flash time values of about $22 \mathrm{~min}$ and less than $1 \mathrm{~min}$ were associated with the storm's life cycle. These values correspond to IC flashes. This parameter can be applied to lightning forecasting or temporal and spatial lightning characterization, and was introduced here only as complementary information (this study does not focus on that parameter).

All in all, stroke clustering is very sensitive to the grouping criteria, which need to be accurately defined, as this will affect several derived lightning parameters, like the ground flash density ( $\mathrm{Ng}$ ). Our results suggest, at least for the region of study, that the stroke-to-flash grouping criteria proposed by Cummins et al. (1998) currently implemented in reference LLS like the NLDN (Continental U.S.) (Rudlosky and Fuelberg, 2010; Orville et al., 2011), or EUCLID (Europe) (Schulz et al., 2016); may be too restrictive, as different ground contact points from the same flash may be classified as different CG flashes. As a practical consequence, the $\mathrm{Ng}$ is oversized.

\subsection{Eccentricity}

Measurements from diverse instruments like electric field change arrays and radar, radio, and acoustic mapping of lightning (e.g. Pierce, 1955; Ogawa and Brook, 1964; Krehbiel et al., 1979; MacGorman et al., 1981; Proctor, 1983), provided evidence on the predominantly horizontal propagation of the lightning channels in the cloud. LMA 3D mapping has shown that many IC flashes have a relatively short vertical channel connecting two extensive horizontal regions of discharge, which often contain a number of horizontal branches (Hill et al., 2013). In fact, the tendency for the storm charges to be horizontally distributed and the electric fields usually or often to be predominantly vertical (Rison et al., 1999) causes intra-cloud discharges to start developing vertically and then horizontally in a storm. van der Velde and Montanyà (2013) had observed the leaders to respawn from the flash origin, typically expanding with multiple simultaneous main branches into various directions.

\subsection{Seasonal differences on lightning characteristics}

It is well known that lightning occurrence and distribution vary by region and season because of differences in atmospheric conditions and their influence on lightning production (Williams, 1992; Rudlosky and Fuelberg, 2011). On continental mid-latitudes, lightning activity is concentrated during the "warm season" (e.g. Poelman et al., 2016; Klugmann et al., 2014; Koshak et al., 2015). Conversely, winter months only account for a little amount of the annual lightning (Poelman et al., 2016). In Europe, winter activity is predominantly restricted to the Mediterranean (e.g. Montanyà et al., 2016; Altaratz et al., 2003; Ziv et al., 2009; Proestakis et al., 2016; Pineda et al., 2011), where warm waters provide the driver for storm development. As land begins to warm in spring, convection begins to switch from sea to land and by early summer. Although this study does not focus on seasonal differences in lightning characteristics, the accuracy of parameters derived from lightning might be affected by imprecise estimations. e.g. when the difference between lightning lengths in summer and winter storms are not taken into account, parameters such as ground flash density can be overor under-estimated. 


\section{Summary}

In the framework of this study, the spatial and temporal lightning dimension have been analyzed conforming to a simple fitting ellipse method. As a result, a length extension for summer lightning of about $15 \mathrm{~km}$ and $10.4 \mathrm{~km}$ for mean and median respectively were found. In winter lightning, the mean and median values were approximately $18.5 \mathrm{~km}$ and $15.5 \mathrm{~km}$ respectively. These results suggest that winter lightning is longer than summer lightning, with mean and median lengths of about $3.4 \mathrm{~km}$ and $5.2 \mathrm{~km}$ respectively. The maximum length of lightning registered was about $143 \mathrm{~km}$ and corresponded to a lightning flash that occurred during a summer storm. In this way, $90 \%$ of summer lightning has an approximate length of $30 \mathrm{~km}$ or below, while in winter lightning this value was about $35 \mathrm{~km}$.

The length of lightning derived from the fit ellipse method showed an uncertainty of about $\pm 1.2 \mathrm{~km}$ and $\pm 0.7 \mathrm{~km}$ when considering the mean and median value respectively for summer lightning. In case of winter lightning, the level of uncertainty reached up to $1 \mathrm{~km}$ and $0.7 \mathrm{~km}$ of mean and median value respectively.

Regarding lightning durations, mean and median values in both seasons were found to be similar. In summer case, those values were about $438 \mathrm{~ms}$ and $354 \mathrm{~ms}$ respectively. Regarding winter lightning, values of about $452 \mathrm{~ms}$ and $413 \mathrm{~ms}$ as mean and median values were reported respectively. In general, $90 \%$ of winter and summer lightning had a duration of up to $800 \mathrm{~ms}$ or below. The maximum lightning durations were approximately $2.4 \mathrm{~s}$ and $1.8 \mathrm{~s}$ in both summer and winter respectively. For the inter-flash lapse durations (the time difference between two consecutive LMA lightning flashes), averages of about $16 \mathrm{~s}$ and $144 \mathrm{~s}$ in summer and winter lightning were reported.

The results of the successful correlation of CG discharges with the EFT method represent $6.9 \%$ and $35.5 \%$ of the total LMA flashes detected in summer and winter respectively. Additionally, the median value of lightning lengths calculated through this correlative method was approximately $17 \mathrm{~km}$ for both seasons. On the other hand, the highest median ratios of lightning length to CG discharges in both summer and winter were reported for positive CG discharges.

With respect to the eccentricity of ellipse (the minor-major axis relationship), about $10 \%$ of the ellipses have an eccentricity below 0.5 (indicating that the major axis value is twice that of the minor axis), approximately $44 \%$ of the ellipses were between 0.5 and 0.75 and the majority of the ellipses (550\%) have an eccentricity above 0.75 .

\section{Acknowledgments}

The authors want to thank the reviewers for their detailed comments and suggestions on the paper.

This work was supported by research grants from the Spanish Ministry of Economy and the European Regional Development Fund (FEDER): MINECOAYA2011-29936-C05-04 and (MINECO/FEDER) ESP2013- 48032-C5-3-R and (MINECO/FEDER) ESP2015-69909-C5-5-R.

\section{References}

Aiya, S., Lakshminarayan, K., 1965. Atmospheric radio noise bursts in the lf band at Bangalore (atmospheric radio noise bursts arising from radiation fields of electrical discharge in lf band at Bangalore, India). J. Res. 69, 1351-1358.

Altaratz, O., Levin, Z., Yair, Y., Ziv, B., 2003. Lightning activity over land and sea on the eastern coast of the Mediterranean. Mon. Weather Rev. 131 (9), 2060-2070.

Ballarotti, M.G., Medeiros, C., Saba, M.M., Schulz, W., Pinto, O., 2012. Frequency distributions of some parameters of negative downward lightning flashes based on accurate-stroke-count studies. J. Geophys. Res. Atmos. 117 (D6)http://dx.doi.org/10. 1029/2011JD017135,2012.

Barnolas, M., Rigo, T., Llasat, M., 2010. Characteristics of 2-D convective structures in Catalonia (NE Spain): an analysis using radar data and GIS. Hydrol. Earth Syst. Sci. 14 (1), 129-139.
Betz, H.D., Schmidt, K., Laroche, P., Blanchet, P., Oettinger, W.P., Defer, E., Dziewit, Z., Konarski, J., 2009. LINET-an international lightning detection network in Europe. Atmos. Res. 91 (2-4), 564-573. http://dx.doi.org/10.1016/j.atmosres.2008.06.012 http://www.sciencedirect.com/science/article/pii/S0169809508002305, 13th International Conference on Atmospheric Electricity - ICAE 2007.

Betz, H.D., Schmidt, K., Oettinger, W.P., 2009. LINET: An International VLF/LF Lightning Detection Network in Europe, Springer.

Boccippio, D.J., Cummins, K.L., Christian, H.J., Goodman, S.J., 2001. Combined satelliteand surface-based estimation of the intracloud-cloud-to-ground lightning ratio over the continental United States. Mon. Weather Rev. 129 (1), 108-122.

Bookstein, F.L., 1979. Fitting conic sections to scattered data. Comput. Graphics Image Process. 9 (1), 56-71, Elsevier.

Brook, M., Kitagawa, N., 1960. Some aspects of lightning activity and related meteorological conditions. J. Geophys. Res. 65 (4), 1203-1210. http://dx.doi.org/10.1029/ JZ065i004p01203, Wiley Online Library.

Bruce, C.E.R., Golde, R.H., 1941. The lightning discharge. J. Inst. Elect. Eng. Part II Power Eng. 88 (6), 487-505, IET

Bruning, E.C., MacGorman, D.R., 2013. Theory and observations of controls on lightning flash size spectra. J. Atmos. Sci. 70 (12), 4012-4029. http://dx.doi.org/10.1175/ JAS-D-12-0289.1.

Bruning, E.C., Thomas, R.J., 2015. Lightning channel length and flash energy determined from moments of the flash area distribution. J. Geophys. Res. Atmos. 120 (17), 8925-8940.

Cummins, K.L., Murphy, M.J., 2009. An overview of lightning locating systems: history, techniques, and data uses, with an in-depth look at the US NLDN. IEEE Trans. Electromagn. Compat. 51 (3), 499-518, IEEE.

Cummins, K.L., Murphy, M.J., Bardo, E.A., Hiscox, W.L., Pyle, R.B., Pifer, A.E., et al., 1998 A combined TOA/MDF technology upgrade of the us national lightning detection network. J. Geophys. Res. 103 (D8), 9035-9044.

Dave, R.N., Bhaswan, K., 1992. Adaptive fuzzy c-shells clustering and detection of ellipses. IEEE Trans. Neural Netw. 3 (5), 643-662, IEEE.

Defer, E., Laroche, P., Dye, J., Skamarock, W., 2003. Use of total lightning lengths to estimate NOx production in a Colorado thunderstorm, paper presented at 12th International Conference on Atmospheric Electricity, June 9-13. Int. Comm. on Atmos. Electr., Versailles, France.

Devadoss, S.L., O'Rourke, J., 2011. Discrete and Computational Geometry. Princeton University Press.

Fitzgibbon, A., Pilu, M., Fisher, R.B., 1999. Direct least square fitting of ellipses. IEEE Trans. Pattern Anal. Mach. Intell. 21 (5), 476-480, IEEE.

Gander, W., Golub, G.H., Strebel, R., 1994. Least-squares fitting of circles and ellipses. BIT Numer. Math. 34 (4), 558-578, Springer.

Goodman, S.J., Blakeslee, R., Christian, H., Koshak, W., Bailey, J., Hall, J., McCaul, E., Buechler, D., Darden, C., Burks, J., et al., 2005. The North Alabama lightning mapping array: recent severe storm observations and future prospects. Atmos. Res. 76 (1) 423-437, Elsevier.

Goodman, S.J., Blakeslee, R.J., Koshak, W.J., Mach, D., Bailey, J., Buechler, D., Carey, L., Schultz, C., Bateman, M., McCaul, E., et al., 2013. The GOES-R geostationary lightning mapper (GLM). Atmos. Res. 125-126, 34-49, Elsevier.

Hazmi, A., Emeraldi, P., Hamid, M.I., Takagi, N., Wang, D., 2017. Characterization of positive cloud to ground flashes observed in Indonesia. Atmosphere 8 (1), 4.

Hill, J., Pilkey, J., Uman, M., Jordan, D., Rison, W., Krebhiel, P., Biggerstaff, M.I., Hyland, P., Blakeslee, R., 2013. Correlated lightning mapping array and radar observations of the initial stages of three sequentially triggered Florida lightning discharges. J. Geophys. Res. Atmos. 118 (15), 8460-8481.

IEC-62305-2, 2013. Iec-62305-2: Protection against lightning-part 2 (risk management). Number 3. 6-90.

Karklinsky, M., Morin, E., 2006. Spatial characteristics of radar-derived convective rain cells over Southern Israel. Meteorol. Z. 15 (5), 513-520, E. Schweizerbart'sche Verlagsbuchhandlung.

Klugmann, D., et al., 2014. A European lightning density analysis using 5 years of ATDnet data. Nat. Hazards Earth Syst. Sci. 14 (4), 815

Koshak, W., Solakiewicz, R., 2011. Retrieving the fraction of ground flashes from satellite lightning imager data using conus-based optical statistics. J. Atmos. Ocean. Technol. 28 (4), 459-473.

Koshak, W.J., Cummins, K.L., Buechler, D.E., Vant-Hull, B., Blakeslee, R.J., Williams, E.R., Peterson, H.S., 2015. Variability of conus lightning in 2003-12 and associated impacts. J. Appl. Meteorol. Climatol. 54 (1), 15-41.

Krehbiel, P.R., Brook, M., McCrory, R.A., 1979. An analysis of the charge structure of lightning discharges to ground. J. Geophys. Res. Oceans 84 (C5), 2432-2456.

Lang, T.J., Pédeboy, S., Rison, W., Cerveny, R.S., Montanyà, J., Chauzy, S., MacGorman, D.R., Holle, R.L., Ávila, E.E., Zhang, Y., et al., 2016. WMO world record lightning extremes: longest reported flash distance and longest reported flash duration. Bull. Am. Meteorol. Soc. (2016).

Leavers, V.F., 1992. Shape Detection in Computer Vision Using the Hough Transform. Springer, London, http://dx.doi.org/10.1007/978-1-4471-1940-1.

MacGorman, D.R., Few, A., Teer, T., 1981. Layered lightning activity. J. Geophys. Res. Oceans 86 (C10), 9900-9910.

Maini, E.S., 2005. Robust ellipse-specific fitting for real-time machine vision. In: International Symposium on Brain, Vision, and Artificial Intelligence. Springer, pp. 318-327.

March, V., 2016. Lightning risk assessment to wind turbines: methodology and guide lines. In: 33rd International Conference on Lightning Protection (ICLP), Estoril. pp. 1-8. http://dx.doi.org/10.1109/ICLP.2016.7791381, iEEE.

McCaul Jr, E.W., Bailey, J., Hall, J., Goodman, S., Blakeslee, R., Buechler, D., 2005. A flash clustering algorithm for North Alabama lightning mapping array data. In: Preprints, Conf. on Meteorological Applications of Lightning data.

McCaul Jr, E.W., Goodman, S.J., LaCasse, K.M., Cecil, D.J., 2009. Forecasting lightning threat using cloud-resolving model simulations. Weather Forecast. 24 (3), 709-729. 
Montanyà, J., Fabró, F., Velde, O.v.d., March, V., Williams, E.R., Pineda, N., Romero, D., Solà, G., Freijo, M., 2016. Global distribution of winter lightning: a threat to wind turbines and aircraft. Nat. Hazards Earth Syst. Sci. 16 (6), 1465-1472. http://dx.doi.org/ 10.5194/nhess-16-1465-2016.

Montanyà, J., van der Velde, O., Solà, G., Fabró, F., Romero, D., Pineda, N., Argemí, O., 2014. Lightning flash properties derived from lightning mapping array data. In: International Conference on Lightning Protection (ICLP), Shanghai, pp. 974-978. http:// dx.doi.org/10.1109/ICLP.2014.6973264, iEEE.

Montanyà, J., Velde, O., Williams, E.R., 2014. Lightning discharges produced by wind turbines. J. Geophys. Res. Atmos. 119 (3), 1455-1462

Ogawa, T., Brook, M., 1964. The mechanism of the intracloud lightning discharge. J. Geophys. Res. 69 (24), 5141-5150. http://dx.doi.org/10.1029/JZ069i024p05141, Wiley Online Library.

Orechovesky, J.R., 1996. Single source error ellipse combination. In: Technical Report, DTIC Document.

Orville, R.E., Huffines, G.R., Burrows, W.R., Cummins, K.L., 2011. The North American lightning detection network (NALDN)-analysis of flash data: 2001-09. Mon. Weather Rev. 139 (5), 1305-1322.

Pédeboy, S., Schulz, W., 2014. Validation of a ground strike point identification algorithm based on ground truth data. In: Proceedings, International Lightning Detection Con ference ILDC.

Pierce, E., 1955. Electrostatic field-changes due to lightning discharges. Q. J. R. Meteorol. Soc. 81 (348), 211-228. http://dx.doi.org/10.1002/qj.49708134808, Wiley Online Library.

Pineda, N., Bech, J., Rigo, T., Montanyà, J., 2011. A Mediterranean nocturnal heavy rainfall and tornadic event. Part II: total lightning analysis. Atmos. Res. 100 (4), 638-648, Elsevier.

Pineda, N., Rigo, T., Montanyà, J., van der Velde, O.A., 2016. Charge structure analysis of a severe hailstorm with predominantly positive cloud-to-ground lightning. Atmos. Res. 178, 31-44, Elsevier.

Poelman, D.R., Schulz, W., Diendorfer, G., Bernardi, M., 2016. The European lightning location system EUCLID-part 2: observations. Nat. Hazards Earth Syst. Sci. 16 (2), 607-616.

Porrill, J., 1990. Fitting ellipses and predicting confidence envelopes using a bias corrected Kalman filter. Image Vis. Comput. 8 (1), 37-41, Elsevier.

Price, C., Rind, D., 1993. What determines the cloud-to-ground lightning fraction in thunderstorms?. Geophys. Res. Lett. 20 (6), 463-466.

Proctor, D., 1983. Lightning and precipitation in a small multicellular thunderstorm. J. Geophys. Res. Oceans 88 (C9), 5421-5440.

Proestakis, E., Kazadzis, S., Lagouvardos, K., Kotroni, V., Kazantzidis, A., 2016. Lightning activity and aerosols in the Mediterranean region. Atmos. Res. 170, 66-75, Elsevier.

Qie, X., Wang, Z., Wang, D., Liu, M., 2013. Characteristics of positive cloud-to-ground lightning in Da Hinggan Ling forest region at relatively high latitude, Northeastern China. J. Geophys. Res. Atmos. 118 (24).

Rakov, V.A., Huffines, G.R., 2003. Return-stroke multiplicity of negative cloud-to-ground lightning flashes. J. Appl. Meteorol. 42 (10), 1455-1462.

Ray, A., Srivastava, D.C., 2008. Non-linear least squares ellipse fitting using the genetic algorithm with applications to strain analysis. J. Struct. Geol. 30 (12), 1593-1602.
Renard, F., Chapon, P.-M., Comby, J., 2012. Assessing the accuracy of weather radar to track intense rain cells in the Greater Lyon Area, France. Atmos. Res. 103, 4-19.

Rison, W., Thomas, R.J., Krehbiel, P.R., Hamlin, T., Harlin, J., 1999. A GPS-based three-dimensional lightning mapping system: initial observations in central new mexico. Geophys. Res. Lett. 26 (23), 3573-3576, Wiley Online Library.

Rudlosky, S.D., Fuelberg, H.E., 2010. Pre- and postupgrade distributions of NLDN reported cloud-to-ground lightning characteristics in the contiguous United States. Mon. Weather Rev. 138 (9), 3623-3633.

Rudlosky, S.D., Fuelberg, H.E., 2011. Seasonal, regional, and storm-scale variability of cloud-to-ground lightning characteristics in Florida. Mon. Weather. Rev. 139 (6), 1826-1843.

Rustan, P.L., Uman, M.A., Childers, D.G., Beasley, W.H., Lennon, C.L., 1980. Lightning source locations from VHF radiation data for a flash at Kennedy Space Center. J. Geophys. Res. Oceans 85 (C9), 4893-4903, Wiley Online Library.

Saba, M.M., Schulz, W., Warner, T.A., Campos, L.Z., Schumann, C., Krider, E.P., Cummins, K.L., Orville, R.E., 2010. High-speed video observations of positive lightning flashes to ground. J. Geophys. Res.-Atmos. 115 (D24).

Sastry, A., 1970. Duration of a lightning flash. J. Atmos. Terr. Phys. 32 (11), 1841IN11843-1842. Elsevier.

Schonland, B., 1956. The lightning discharge. Hand. Phys. 22, 576-628, Springer Verlag.

Schulz, W., Diendorfer, G., Pedeboy, S., Poelman, D.R., 2016. The European lightning location system EUCLID-part 1: performance analysis and validation. Nat. Hazards Earth Syst. Sci. 16 (2), 595-605.

Stall, C.A., Cummins, K.L., Krider, E.P., Cramer, J.A., 2009. Detecting multiple ground contacts in cloud-to-ground lightning flashes. J. Atmos. Ocean. Technol. 26 (11), 2392-2402.

Stano, G.T., Fuelberg, H.E., Roeder, W.P., 2010. Developing empirical lightning cessation forecast guidance for the Cape Canaveral Air Force Station and Kennedy Space Center. J. Geophys. Res.-Atmos. 115 (D9), Wiley Online Library.

Thomas, R., Krehbiel, P., Rison, W., Burning, E., 2013. Lightning flash length estimation from lightning mapping array measurements. In: 6th Conf. on the Meteorol. App. of Lightning Data Proceedings.

Thomas, R., Krehbiel, P., Rison, W., Harlin, J., Hamlin, T., Campbell, N., 2003. The LMA flash algorithm. In: Proc. 12th Int. Conf. on Atmospheric Electricity. pp. 655-656.

van der Velde, O.A., Montanyà, J., 2013. Asymmetries in bidirectional leader development of lightning flashes. J. Geophys. Res.-Atmos. 118 (24).

Wang, B., Shi, W., Miao, Z., 2015. Confidence analysis of standard deviational ellipse and its extension into higher dimensional Euclidean space. PloS one 10 (3), e0118537, Public Library of Science.

Williams, E.R., 1992. The Schumann resonance: a global tropical thermometer. Science 256 (5060), 1184, The American Association for the Advancement of Science.

Yair, Y., Shalev, S., Erlich, Z., Agrachov, A., Katz, E., Saaroni, H., Price, C., Ziv, B., 2014 Lightning flash multiplicity in eastern Mediterranean thunderstorms. Nat. Hazards Earth Syst. Sci. 14 (2), 165, Copernicus GmbH.

Ziv, B., Saaroni, H., Yair, Y., Ganot, M., Baharad, A., Isaschari, D., 2009. Atmospheric factors governing winter thunderstorms in the coastal region of the eastern Mediterranean. Theor. Appl. Climatol. 95 (3-4), 301, Springer. 